\title{
Purwarupa Pengendalian Jarak Jauh Pada Mobile Robot Berbasis Web Melalui Jaringan Wireless TCP/IP
}

\author{
Fajar Rinto Hadi Putra*1, Tri Kuntoro Priyambodo ${ }^{2}$ \\ ${ }^{1}$ Program Studi Elektronika dan Instrumentasi, JIKE, FMIPA, UGM, Yogyakarta \\ ${ }^{2}$ Departemen Ilmu Komputer dan Elektronika, Universitas Gadjah Mada, Yogyakarta \\ e-mail: ${ }^{\text {11 }}$ fajarrintohp@gmail.com, ${ }^{2}$ mastri@ ugm.ac.id
}

\begin{abstract}
Abstrak
Telah berhasil dirancang sebuah purwarupa mobile robot yang dapat dikendalikan dari jarak jauh, dengan berbasis web melalui jaringan TCP/IP. Purwarupa mobile robot menggunakan sistem gerak menyerupai tank, yang dilengkapi sebuah kamera untuk keperluan surveillance untuk mendapatkan data pantauan lingkungan secara real time di sekitar mobile robot ini, pengguna menggunakan webcam. Karena purwarupa mobile robot ini dapat dikendalikan dari jarak jauh menggunakan aplikasi berbasis web dari komputer host melalui media jaringan wireless TCP/IP, ditujukan untuk keperluan penginderaan jarak jauh di lingkungan yang berbahaya bagi keselamatan manusia. Komunikasi yang dilakukan menggunakan sebuah perangkat wireless untuk dua arah mengirim dan menerima data. Pada tahap debugging, komunikasi wireless dilakukan tanpa penghalang (line of sight), antara komputer host dengan purwarupa mobile robot tersebut.
\end{abstract}

Kata kunci-mobile robot, komunikasi wireless, TCP/IP

\begin{abstract}
It has been successfully developed a prototype mobile robot, controlled remotely, based on web via wireless TCP/IP network. This prototype mobile robot adopts tank's movement, equipped with a surveillance camera to acquire real time data on surrounding environment, a webcam is used by user. Since it is controlled remotely from a web based application on host computer via wireless TCP/IP network, it could do some telemetry in such environment, which harmful for human. It uses a wireless device for birectional communication, to transmit and receive data. While on debugging, wireless communication are took place directly without any obstacle (line of sight), between host computer and prototype mobile robot.
\end{abstract}

Keywords - mobile robot, wireless communication, TCP/IP 


\section{PENDAHULUAN}

$\mathrm{D}^{\mathrm{s}}$ lam menjalankan tugasnya sehari-hari, beberapa profesi menuntut kehadiran manusia pada lingkungan kerja yang berbahaya, seperti lingkungan yang tercemar unsur radioaktif, daerah yang mengandung gas beracun, goa pertambangan, ataupun tempat yang belum pernah dan sulit dijamah oleh manusia.

Dalam rangka mengurangi resiko kecelakaan dan bahaya secara langsung, maka diperlukan suatu alat yang dapat menggantikan kehadiran manusia pada lokasi-lokasi tersebut. Peralatan tersebut diharuskan dapat mewakili peran manusia pada lokasi yang dimaksud yaitu dapat memberikan informasi dari suatu lokasi ke stasiun pemantau dengan jarak yang jauh. Dengan demikian akan lebih menjamin keselamatan manusia, informasi yang diperlukan dari suatu lokasi tetap bisa didapatkan dan dipantau secara berkelanjutan. Salah satu solusi yang dapat menjawab permasalahan di atas adalah dengan mengembangkan unmanned vehicle untuk keperluan surveillance yang salah satunya diwujudkan dalam bentuk mobile robot. Robot adalah peralatan elektro-mekanik atau bio-mekanik, atau gabungan peralatan yang menghasilkan gerakan otonomi maupun berdasarkan gerakan yang diperintahkan [1]. Robot yang dilengkapi dengan peralatan komunikasi dimungkinkan untuk dikendalikan dari jarak jauh [2] serta memungkinkan untuk melakukan pengiriman informasi [3] dari suatu lokasi ke stasiun pemantau.

Salah satu peralatan yang dikendalikan berupa sebuah robot yang dilengkapi dengan kamera untuk keperluan pengendalian dan pemantauan sehingga operator tetap dapat mengendalikan robot tanpa harus melihat posisi robot. Sistem yang diadopsi berupa sistem penglihatan (mata), sistem pendengaran (telinga) ataupun sistem gerak [4], sehingga robot bergerak dengan kecerdasan yang telah diprogramkan [5]. Selain itu, peralatan jaringan komputer saat ini relatif mudah di dapat dan harganya cukup terjangkau serta mudah untuk dilakukan pengembangan jaringan. Dalam penelitian ini akan dikembangkan sebuah purwarupa mobile robot yang dilengkapi dengan kamera untuk keperluan surveillance yang dapat dikontrol secara jarak jauh menggunakan aplikasi berbasis web dari komputer user/client melalui media jaringan wireless TCP/IP.

\section{METODE PENELITIAN}

\subsection{Perancangan Perangkat Keras}

Robot yang dikembangkan merupakan mobile robot dengan sistem penggerak tank (track). Robot dirancang untuk dapat dikendalikan dari jarak jauh melalui jaringan wireless TCP/IP dengan antarmuka aplikasi berbasis web yang dibenamkan pada Raspberry Pi [6] yang langsung terintegrasi dengan robot yang sekaligus berfungsi sebagai web server. Robot dilengkapi dengan kamera webcam sebagai kamera navigasi bagi operator untuk mengendalikan robot. Hasil visualisasi dari kamera akan ditampilkan secara real time pada halaman web. Komputer client/user (operator) bersifat fleksibel yang tidak terbatas pada komputer tertentu. Operator cukup memanggil alamat IP robot untuk dapat mengakses halaman web untuk mengendalikan robot. Gambar 1 menunjukkan blok diagram pengendalian mobile robot jarak jauh berbasis web dengan media jaringan wireless TCP/IP. 


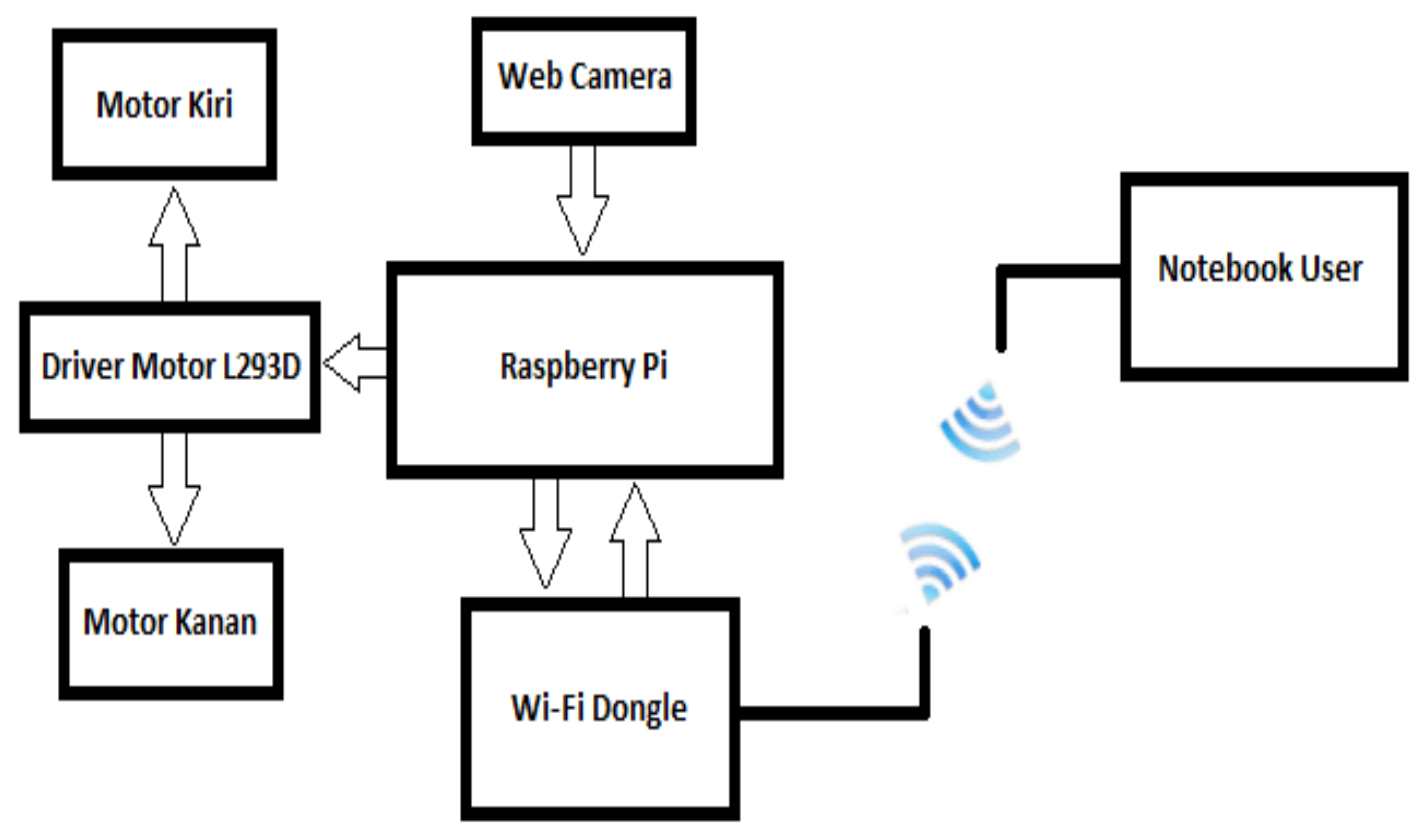

Gambar 1 Diagram blok sistem mobile robot

Raspberry Pi sebagai pusat kendali robot menerima input dari web camera dan perintah dari user. Berdasarkan perintah dari user, Raspberry Pi akan memberikan sinyal output untuk driver L293D untuk mengendalikan motor kiri dan kanan. Untuk berkomunikasi dengan user, Raspberry Pi menggunakan perangkat tambahan USB Wi-Fi dongle.

\subsection{Perancangan Perangkat Lunak}

Perancangan perangkat lunak pada penelitian ini teridiri atas tiga bagian, yaitu instalasi perangkat lunak yang digunakan pada Raspberry $\mathrm{Pi}$, konfigurasi pengendalian gerakan robot, dan konfigurasi halaman web. Perangkat lunak pendukung yang digunakan antara lain, mjpegstreamer, lighttpd, konfigurasi jaringan. Program pengendali gerakan robot digunakan dengan menggunakan perangkat lunak Python. Diagram alir program pengendalian gerakan robot ditunjukan oleh Gambar 2. 


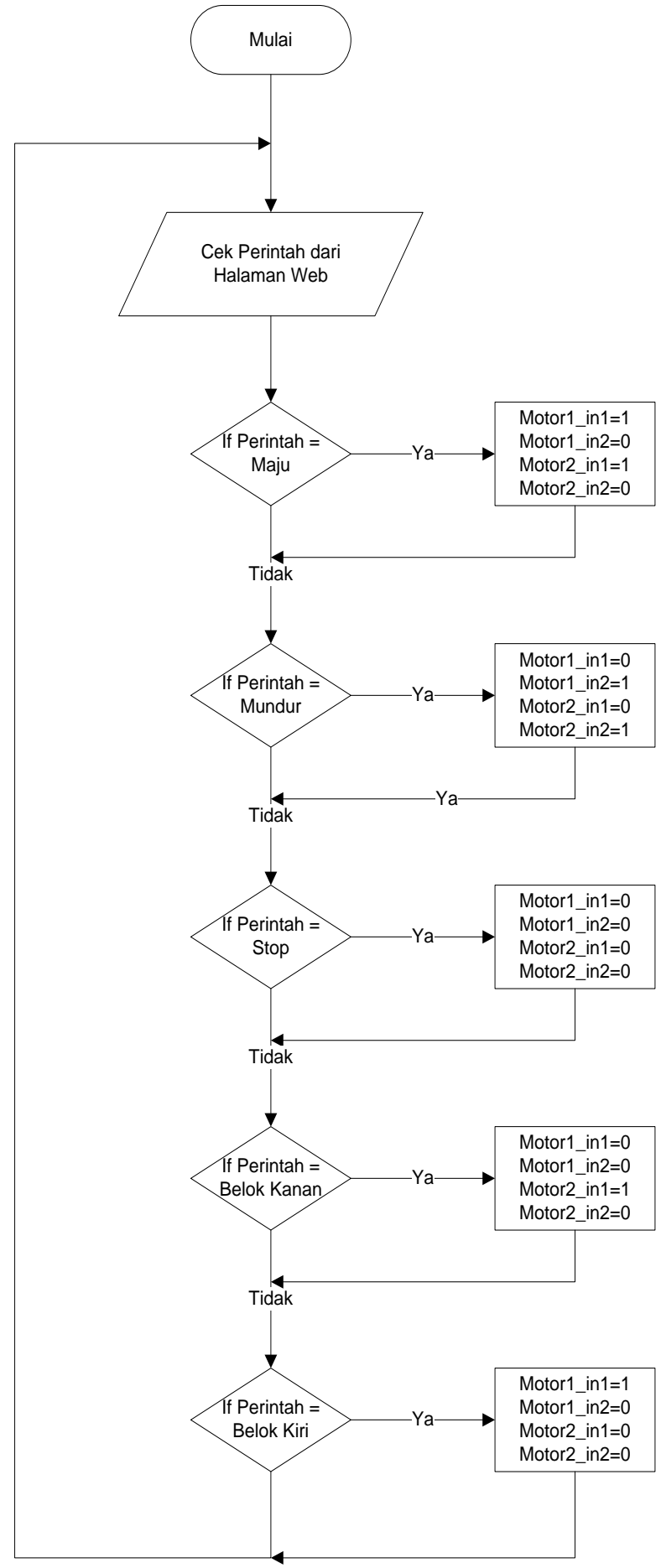

Gambar 2 Diagram alir program kendali Python

Halaman web yang menjadi antarmuka untuk mengendalikan robot terdiri atas frame video yang berfungsi untuk menampilkan video streaming dari robot yang digunakan untuk navigasi dalam mengendalikan robot, tombol panah maju untuk memerintahkan robot bergerak maju, tombol panah ke kanan untuk memerintahkan robot berbelok ke kanan, tombol panah kiri, untuk memerintahkan robot berbelok ke kiri, tombol panah mundur untuk memerintahkan robot bergerak mundur, serta tombol stop untuk memerintahkan robot berhenti. Tampilan antarmuka web untuk mengendalikan robot dapat dilihat seperti pada Gambar 3. 


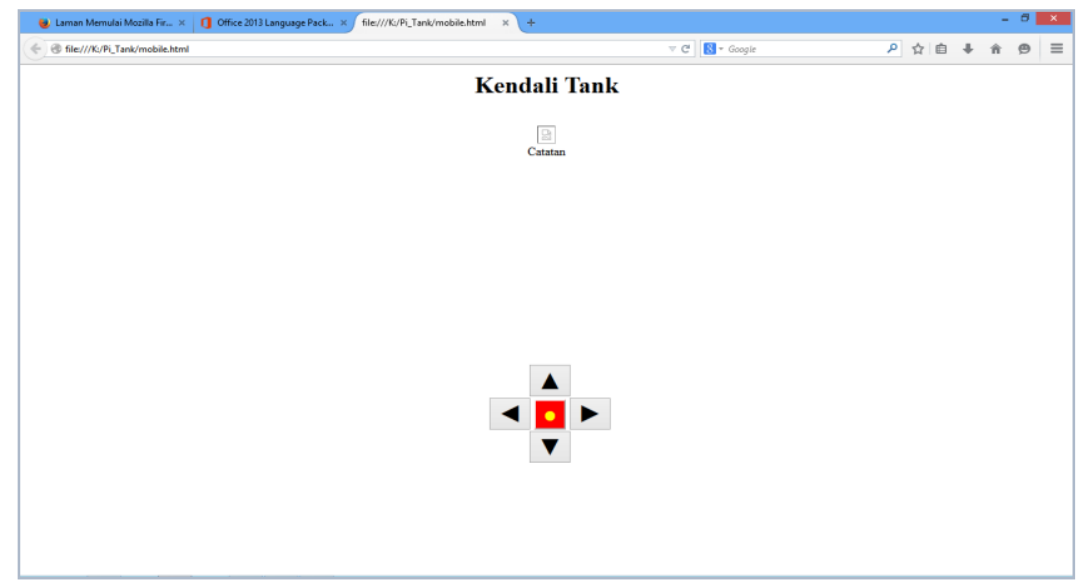

Gambar 3 Antarmuka kendali web mobile robot

Halaman web yang menjadi antarmuka untuk mengendalikan robot terdiri atas frame video yang berfungsi untuk menampilkan video streaming dari robot yang digunakan untuk navigasi dalam mengendalikan robot, tombol panah maju untuk memerintahkan robot bergerak maju, tombol panah ke kanan untuk memerintahkan robot berbelok ke kanan, tombol panah kiri, untuk memerintahkan robot berbelok ke kiri, tombol panah mundur untuk memerintahkan robot bergerak mundur, serta tombol stop untuk memerintahkan robot berhenti. Adapun Gambar 4 menunjukkan arsitektur sederhana web untuk pengendalian mobile robot.

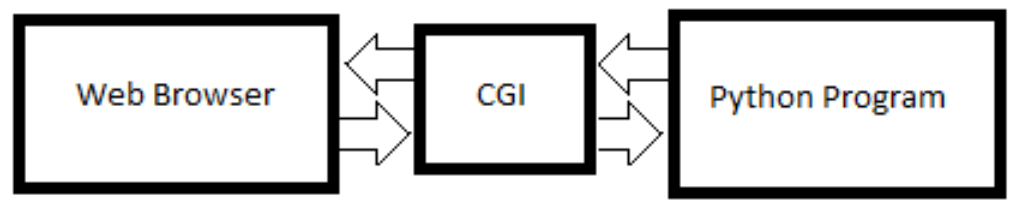

Gambar 4 Arsitektur sederhana web

Untuk web browser bersifat user-end, menampilkan data streaming video dan button kendali yang diperlukan user. Sedangkan pada sisi robot terdapat program Python, yang akan menjalankan input request dari user melalui web browser. Untuk menjembatani antara web browser dengan program Python, diperlukan CGI (Common Gateway Interface) yakni dengan FCGI. Fungsi dari CGI ialah menjembatani antara web browser dengan program Python, menerima request dari web browser untuk disampaikan ke program Python, dan bila request tersebut sesuai, maka akan dijalankan oleh program Python tersebut. Selanjutnya program Python juga akan memberikan tanggapan balik atas request tersebut kepada user (web browser), juga melalui CGI terlebih dahulu.

\subsection{Perancangan Pengujian}

Perancangan pengujian untuk mendapatkan data untuk analisis pencapaian hasil penelitian. Pengujian yang dilakukan meliputi jarak optimal komunikasi wireless, kemampuan mobilitas robot, dan kemampuan respon robot. Tabel 1 menunjukkan data pengujian dan capaian yang diharapkan. 
Tabel 1 Pengujian dan capaian yang diharapkan

\begin{tabular}{|c|l|l|}
\hline No & \multicolumn{1}{|c|}{ Pengujian } & \multicolumn{1}{|c|}{ Capaian } \\
\hline 1 & $\begin{array}{l}\text { Jarak Komunikasi Optimal Wireless TCP/IP } \\
\text { Robot }\end{array}$ & Diketahui jarak optimal pengendalian robot \\
\hline 2 & Kemampuan Mobilitas Robot & $\begin{array}{l}\text { Diketahui kemampuan mobilitas robot } \\
\text { dalam gerakan maju, mundur, belok kanan, } \\
\text { belok kiri, serta kecepatan robot }\end{array}$ \\
\hline 3 & $\begin{array}{l}\text { Respon Robot Terhadap Kendali Manual } \\
\text { Melalu Web }\end{array}$ & $\begin{array}{l}\text { Didapat respon terbaik robot dalam } \\
\text { menanggapi setiap masukan kendali manual } \\
\text { dari web. }\end{array}$ \\
\hline
\end{tabular}

\section{HASIL DAN PEMBAHASAN}

\subsection{Pengujian Variasi Jarak Pengendalian Robot terhadap Kualitas Wi-Fi}

Pelemahan sinyal wireless dipengaruhi oleh banyak faktor, seperti penyerapan, pemantulan, pemecahan, pembelokan sinyal, dan Free Space Path Loss atau FSPL. Pengujian mobile robot dilakukan di lingkungan tanpa penghalang tembok. Meski banyak faktor yang mempengaruhi pelemahan sinyal wireless, namun dalam analisis yang dilakukan hanya mencakup faktor FSPL. Hal tersebut dikarenakan faktor pelemahan sinyal lain sangat terpengaruh pada faktor lingkungan tempat pengujian mobile robot tersebut.

Faktor Free Space Path Loss (FSPL), yakni banyaknya kekuatan sinyal yang hilang (melemah) dalam ruang bebas tanpa hambatan yang berbanding lurus dengan jarak sumber sinyal. Besarnya pelemahan sinyal dari faktor FSPL akan dibandingkan dengan hasil pengukuran dengan aplikasi inSSIDer 2.0. Persamaan (1) menunjukkan analisis perhitungan nilai pelemahan sinyal FSPL.

$F S P L=20 \log d+20 \log f+K$

Keterangan d ialah jarak, $\mathrm{f}$ ialah frekuensi, dan $\mathrm{K}$ ialah konstanta yang nilainya tergantung dari satuan dari d dan $\mathrm{f}$. Bila d dalam $\mathrm{km}$ dan $\mathrm{f}$ dalam $\mathrm{MHz}$ maka nilai $\mathrm{K}$ ialah 33,44, sedangkan jika f dalam $\mathrm{GHz}$, maka nilai $\mathrm{K}$ ialah 92,45. Berbeda lagi bila d dalam meter dan $\mathrm{f}$ dalam MHz, maka nilai $\mathrm{K}$ ialah -27,55. Berdasarkan Persamaan 1 pelemahan FSPL dengan frekuensi wireless yang digunakan ialah $2,4 \mathrm{GHz}$, jarak pengujian 1,2 meter, maka dapat dihitung besarnya pelemahan sinyal seperti pada perhitungan di bawah ini :

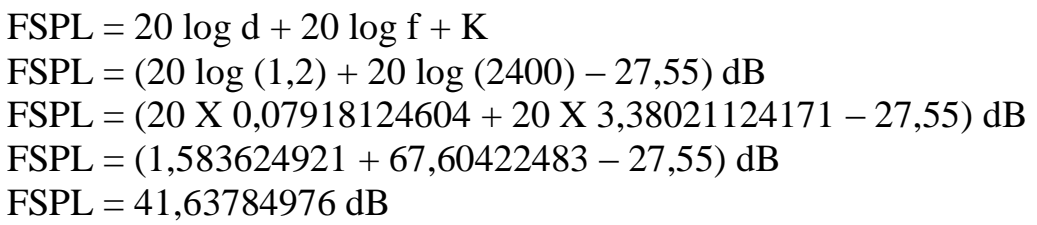

Diperoleh nilai pelemahan FSPL sebesar 41,63784976 dB, yang dibulatkan menjadi 41,64 dB. Karena merupakan suatu pelemahan sinyal maka nilai tersebut menjadi negatif, sehingga menjadi $-41,64 \mathrm{~dB}$. Dengan persamaan yang sama kemudian dilakukan perhitungan kembali untuk variasi jarak yang berbeda-beda, dengan interval 1,2 meter. Data perhitungan jarak terhadap kekuatan sinyal, tampak pada Tabel 2. 
Tabel 2 Data Perhitungan kekuatan sinyal berbanding terhadap jarak

\begin{tabular}{|c|c|c|}
\hline No. & Jarak $(\mathrm{m})$ & $\begin{array}{c}\text { Kekuatan Sinyal } \\
(\mathrm{dB})\end{array}$ \\
\hline 1 & 1,20 & $-41,64$ \\
\hline 2 & 2,40 & $-47,66$ \\
\hline 3 & 3,60 & $-51,18$ \\
\hline 4 & 4,80 & $-53,68$ \\
\hline 5 & 6,00 & $-55,62$ \\
\hline 6 & 7,20 & $-57,20$ \\
\hline 7 & 8,40 & $-58,54$ \\
\hline 8 & 9,60 & $-59,70$ \\
\hline 9 & 10,80 & $-60,72$ \\
\hline
\end{tabular}

Sementara itu kekuatan sinyal yang terukur dengan aplikasi ialah pada Tabel 3 data pengukuran kekuatan sinyal berbanding terhadap jarak.

Tabel 3 Data pengukuran kekuatan sinyal berbanding terhadap jarak

\begin{tabular}{|c|c|c|c|}
\hline No. & Jarak $(\mathrm{m})$ & Kekuatan Sinyal $(\mathrm{dB})$ & Time Reply $(\mathrm{ms})$ \\
\hline 1 & 0 & -44 & 771 \\
\hline 2 & 1.20 & -53 & 519 \\
\hline 3 & 2.40 & -77 & 616 \\
\hline 4 & 3.60 & -67 & 627 \\
\hline 5 & 4.80 & -65 & 636 \\
\hline 6 & 6.00 & -72 & 704 \\
\hline 7 & 7.20 & -77 & 798 \\
\hline 8 & 8.40 & -80 & 0 \\
\hline 9 & 9.60 & -82 & 0 \\
\hline 10 & 1080 & -82 & 0 \\
\hline
\end{tabular}

Jarak pengujian diambil dengan interval setiap 1,2 meter. Kekuatan sinyal dalam dB dengan nilai negatif menandakan pelemahan sinyal. Mulai pada data jarak ke-8, yakni 8,4 meter sinyal sudah sangat melemah hingga tidak lagi memberikan tanggapan balik, time out service. Dari data pengujian tersebut dapat direpresentasikan dalam sebuah grafik antara jarak $(\mathrm{mm})$ sumbu X, dengan kekuatan sinyal (dB) sumbu Y, tampak pada Gambar 5.

Berdasarkan pada data Tabel 2 dan Tabel 3, dapat disusun Gambar 5, grafik perbandingan antara hasil perhitungan dengan pengukuran pelemahan sinyal dengan aplikasi menggunakan inSSIDer 2.0. Garis berwarna jingga merepresentasikan hasil perhitungan pelemahan sinyal, sedangkan garis dengan warna biru untuk pengukuran pelemahan sinyal dengan aplikasi inSSIDer 2.0. 


\section{Grafik Pelemahan Sinyal Terhadap Jarak}

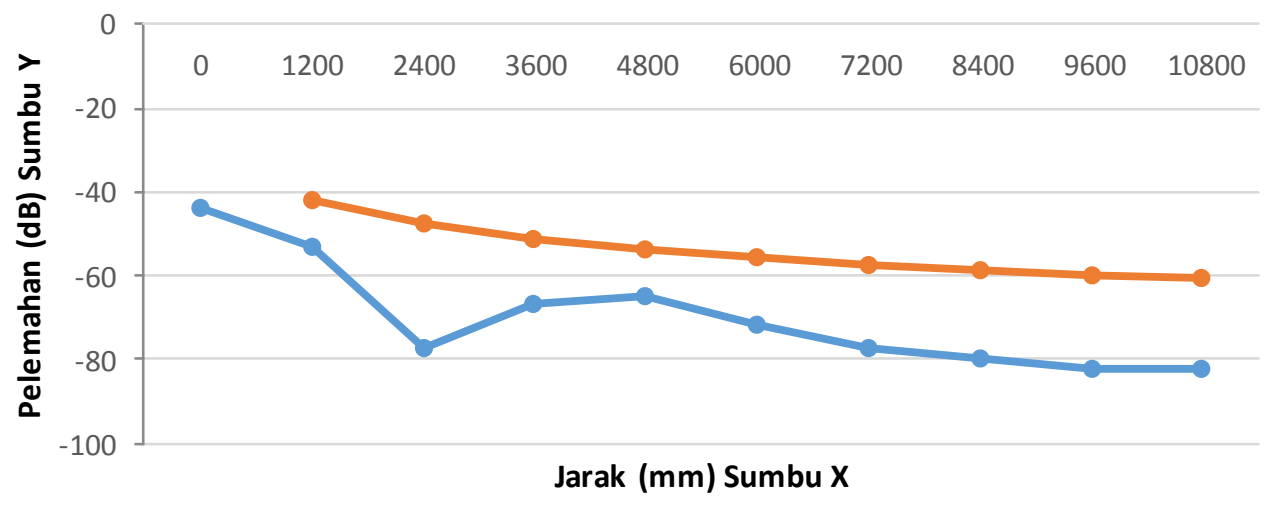

Gambar 5 Grafik jarak dengan kekuatan sinyal

Terdapat selisih antara hasil perhitungan dengan pengukuran dengan inSSIDer 2.0. Dimana pelemahan yang terukur dengan inSSIDer 2.0 lebih besar. Hal tersebut dapat ditolerir, mengingat banyak faktor yang menyebabkan pelemahan sinyal dan semua itu diukur dengan inSSIDer 2.0, sedangkan untuk hasil perhitungan hanya berdasarkan faktor FSPL saja.

\subsection{Pengujian Waktu Tanggap Mobile Robot}

Round trip delay time (RTD) atau round trip time (RTT), terkadang juga disebut ping time, merupakan lamanya waktu yang diperlukan oleh sebuah sinyal untuk dikirimkan ditambah dengan lamanya waktu untuk sinyal acknowledge diterima. Dengan kata lain RTT ialah lamanya waktu yang diperlukan suatu sinyal dari source (sumber) yang dikirimkan ke suatu destination (tujuan), dan kembali ke source dengan memberikan acknowledge paket data terkirim atau tidak. Untuk analisis kaitan antara jarak dengan RTT hanya akan ada pada data yang diperoleh dengan menggunakan aplikasi. Gambar 6 grafik data waktu reply atau RTT terhadap jarak berdasarkan pada Tabel 3 .

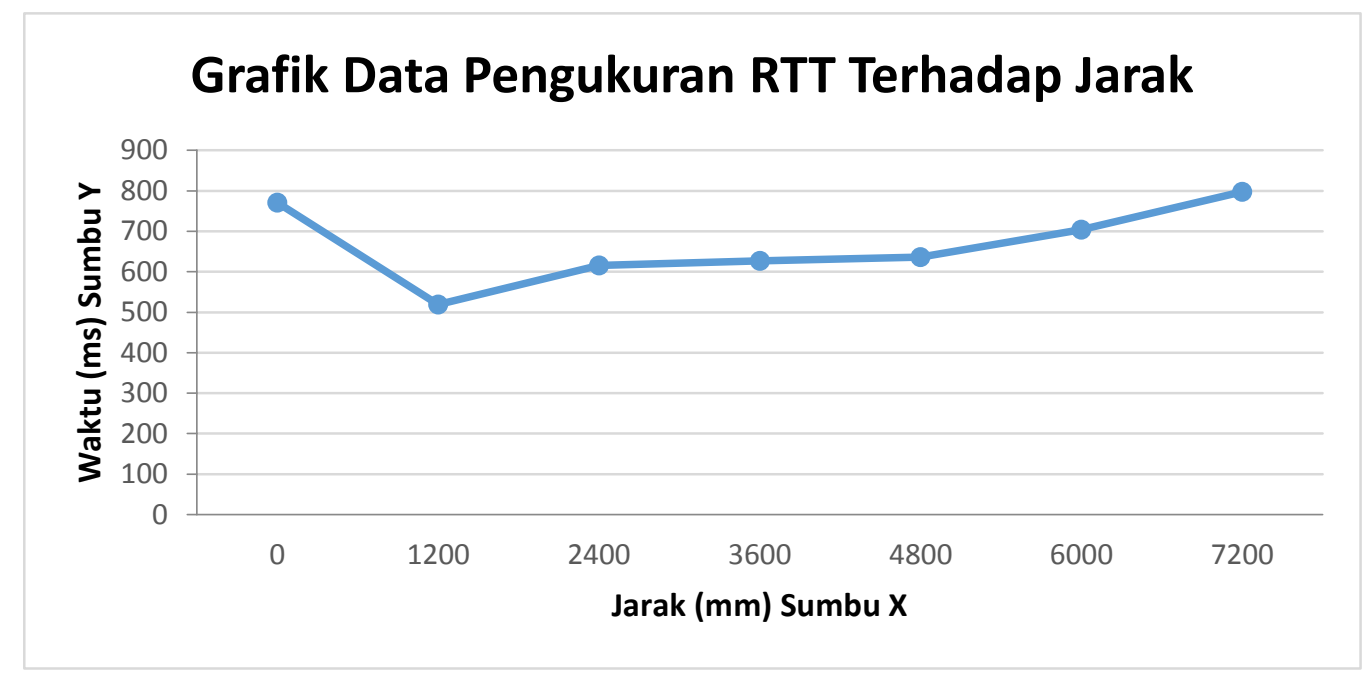

Gambar 6 Grafik jarak dengan waktu reply

Pada Gambar 6, sumbu X untuk jarak dalam mm dan sumbu Y untuk waktu reply (RTT) dalam ms. Pada grafik Gambar 6 tersebut hanya menampilkan data hingga jarak 7200 
mm (7,2 meter), karena berdasarkan data pada Tabel 2 setelah jarak lebih dari itu reply time out, tidak ada balasan. Berdasarkan grafik Gambar 6 dan Tabel 2, terdapat kecenderungan semakin jauh dari sumber, maka waktu reply semakin lama. Selain itu diperoleh pula jarak efektif yang disarankan yakni tidak lebih dari 7,2 meter.

\subsection{Pengujian Kemampuan Streaming Video}

Pengujian kualitas kemampuan streaming video dilakukan dengan merubah nilai framerate dan resolusi video kemudian melihat penggunaan resource CPU pada Raspberry Pi sehingga diharapkan dapat diketahui nilai resolusi dan framerate yang paling baik yang dapat digunakan oleh mobile robot. untuk data hasil pengujian resolusi video dan resource CPU yang digunakan ditunjukan pada Tabel 4.

Tabel 4 Data pengujian streaming video

\begin{tabular}{|c|c|c|}
\hline Resolusi & Framerate & CPU Usage \\
\hline $320 \times 240$ & $15 \mathrm{fps}$ & $0,3 \%$ \\
\hline $640 \times 480$ & $15 \mathrm{fps}$ & $1,6 \%$ \\
\hline $640 \times 480$ & $25 \mathrm{fps}$ & $1,6 \%$ \\
\hline $1024 \times 720$ & $25 \mathrm{fps}$ & $1,6 \%$ \\
\hline $1024 \times 720$ & $30 \mathrm{fps}$ & $1,6 \%$ \\
\hline $\begin{array}{c}720 \mathrm{p}(\mathrm{HD}) \\
(1280 \times 720)\end{array}$ & Not supported & Not supported \\
\hline $\begin{array}{c}1080 \mathrm{p}(\mathrm{Full} H \mathrm{HD}) \\
(1920 \times 1080)\end{array}$ & Not supported & Not supported \\
\hline
\end{tabular}

Pada pengujian streaming video ini, divariasikan beberapa resolusi dan framerate video untuk aplikasi mjpg_streamer, yaitu 320x240 pada $15 \mathrm{fps}$, 640x480 pada $15 \mathrm{fps}$, 640x480 pada $25 \mathrm{fps}, 1024 \times 720$ pada $25 \mathrm{fps}, 1024 \times 720$ pada 30fps, serta video HD 720p (1280x720), dan video full HD 1080p (1920x1080). Pada pengujian video dengan resolusi mulai 320x240 sampai $1024 \times 720$ dan dengan framerate antara 15 fps sampai $30 \mathrm{fps}$, diperoleh nilai rata-rata penggunaan CPU sebesar 1,34\%.

Sedangkan untuk video HD 720p dengan resolusi 1280x 1080 serta video full HD 1080p dengan resolusi 1920x1080, kemampuan webcam belum mendukung. Berdasarkan data pada Tabel 4, pada pengujian ini diketahui bahwa untuk melakukan streaming video dengan resolusi $320 \times 240$ pada framerate 15 fps resource CPU yang digunakan hanyalah sebesar 0,3\%, sedangkan untuk video dengan resolusi lebih tinggi antara 640x480 sampai 1024x720 dengan framerate $15 \mathrm{fps}$ sampai $30 \mathrm{fps}$, resource CPU yang digunakan relatif sama yaitu sebesar 1,6\%.

Dengan demikian dapat disimpulkan bahwa kualitas video optimal yang dapat diaplikasikan pada mobile robot yaitu video dengan tingkat resolusi 1024x720 dengan framerate 25 atau 30 frame per second. Hasil streaming video ditampilkan pada sebuah frame di halaman antarmuka web pengendali mobile robot.

Hanya saja sudut pandang yang ditangkap oleh web camera yang terintegrasi dengan mobile robot masih bersifat tetap, yakni hanya satu arah lurus ke depan. Hal ini tentu saja membatasi kemampuan dari mobile robot untuk surveillance dan mengirimkan informasi lingkungan di sekitarnya melalui streaming video. Adapun Gambar 7 menampilkan hasil tampilan streaming video dari web camera mobile robot. 


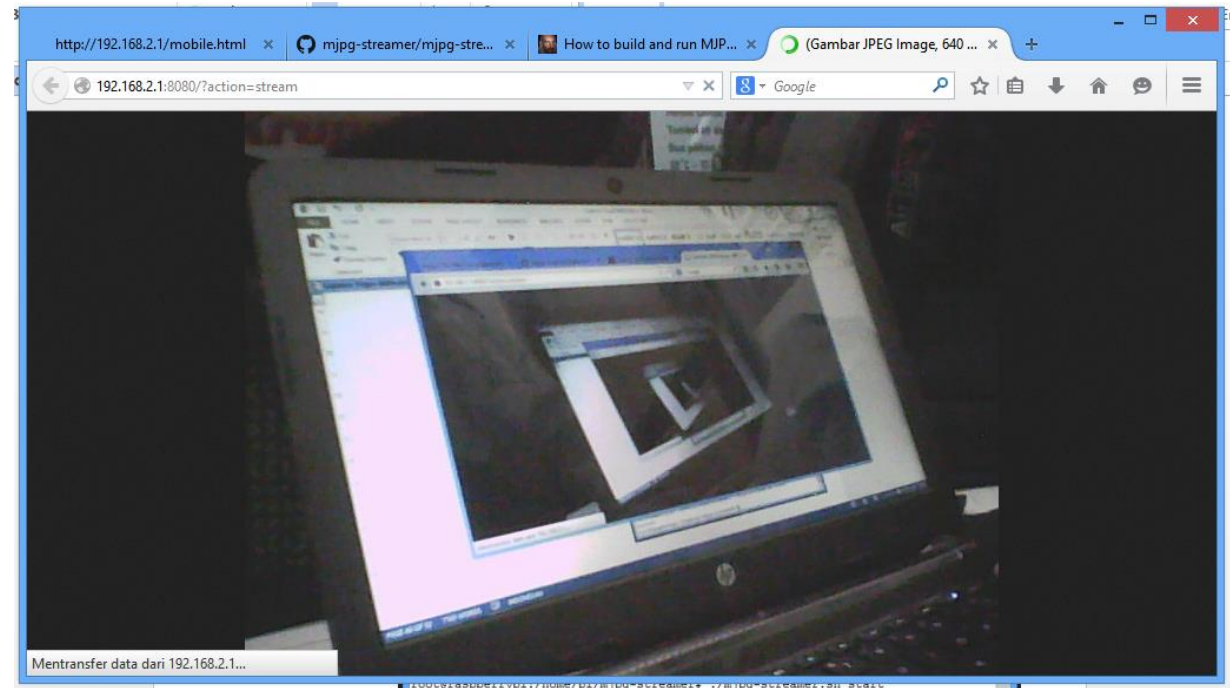

Gambar 7 Hasil streaming video kamera mobile robot

\subsection{Pengujian Kendali Mobile Robot}

Pengujian kendali mobile robot dilakukan dengan cara melakukan analisis terhadap kemampuan dari mobile robot tersebut untuk menjalankan perintah dari user melalui web browser. Parameter yang digunakan untuk menilai berhasil atau tidaknya pengendalian gerak mobile robot ini ialah kesesuaian antara perintah yang diberikan oleh user melalui web browser dengan pergerakan dari mobile robot tersebut. Bila terdapat hasil yang tidak sesuai antara perintah yang diberikan oleh user melalui web browser dengan hasil pergerakan dari mobile robot tersebut, maka hasil pengujian gerak mobile robot tersebut gagal, sehingga diperlukan perbaikan dalam sistem, baik dari perangkat keras maupun perangkat lunak. Lain halnya bila, pergerakan dari mobile robot tersebut sesuai dengan perintah dari user, meski terlambat menjalankannya, maka hal tersebut akan dianggap sebagai sebuah keberhasilan. Adapun Gambar 8 menunjukkan tampilan mobile robot dalam proses pengujian pergerakan.

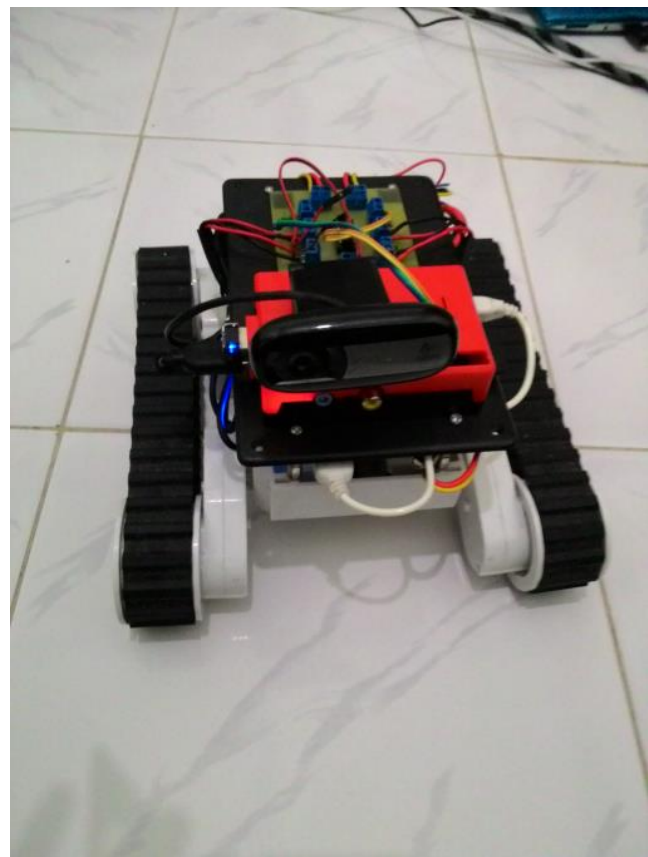

Gambar 8 Tampilan mobile robot 
Hasil pengujian kendali mobile robot disajikan sebagaimana pada Tabel 5 yang berisikan perintah dan pencapaian dari mobile robot tersebut.

Tabel 5 Pengujian kendali mobile robot

\begin{tabular}{|c|c|c|}
\hline Nomor & Perintah & Hasil \\
\hline 1 & Maju & Berhasil \\
\hline 2 & Mundur & Berhasil \\
\hline 3 & Belok Kanan & Berhasil \\
\hline 4 & Belok Kiri & Berhasil \\
\hline
\end{tabular}

Berdasarkan pada Tabel 5 data hasil pengujian kendali mobile robot tersebut mampu melakukan gerak yang sesuai dengan perintah yang diberikan oleh user melalui web browser. Untuk mengatur kerja motor sehingga diperoleh gerak mobile robot maju, mundur, juga berbelok, Raspberry Pi memberikan sinyal kendali output pada port GPIO ke driver motor. Berikut ini ialah Tabel 6 kendali motor.

Tabel 6 Kendali motor

\begin{tabular}{|l|c|c|c|c|l|l|l|}
\hline \multirow{2}{*}{ Nomor } & \multicolumn{4}{|c|}{ GPIO Raspberry Pi } & \multirow{2}{*}{ Gerak Robot } & \multicolumn{1}{c|}{$\begin{array}{c}\text { Motor } \\
\text { Kiri }\end{array}$} & $\begin{array}{c}\text { Motor } \\
\text { Kanan }\end{array}$ \\
\cline { 2 - 5 } & $\mathbf{2 2}$ & $\mathbf{2 4}$ & $\mathbf{2 5}$ & $\mathbf{2 7}$ & & On & On \\
\hline 1 & High & High & Low & Low & Maju & Reverse & Reverse \\
\hline 2 & Low & Low & High & High & Mundur & On & Off \\
\hline 3 & Low & High & Low & Low & Belok Kanan & Off & On \\
\hline 4 & High & Low & Low & Low & Belok Kiri & & \\
\hline
\end{tabular}

Berdasarkan pada Tabel 6, kerja dari kedua motor dikendalikan dengan empat buah port GPIO Raspberry Pi. Kendali motor yang dilakukan bersifat on-off dan dengan pengaturan polaritas dari motor tersebut. Berdasarkan pada Tabel 6 , kondisi motor on berarti motor berputar mengakibatkan robot bergerak maju, reverse putaran motor mengakibatkan robot bergerak mundur, dan off artinya motor tidak aktif.

Untuk dapat mengendalikan motor di sisi kanan agar menghasilkan suatu gerakan maju maka port GPIO 22 harus bernilai high dan port GPIO 25 bernilai low. Demikian pula sebaliknya, untuk menghasilkan gerakan mundur maka port GPIO 25 harus bernilai high dan port GPIO 22 bernilai low. Kedua port GPIO 22 dan 25 tidak boleh bernilai high pada saat yang bersamaan, karena hal tersebut dapat merusak driver motor. Akan tetapi diperbolehkan kedua port GPIO tersebut untuk bernilai low pada saat yang bersamaan.

Sementara untuk mengendalikan motor di sisi kiri agar menghasilkan gerakan maju maka port GPIO 24 harus bernilai high dan port GPIO 27 bernilai low. Demikian pula sebaliknya, untuk menghasilkan gerakan mundur maka port GPIO 27 harus bernilai high dan port GPIO 24 bernilai low. Sama seperti pada motor kanan, kedua port GPIO 24 dan 27 tidak boleh bernilai high, tetapi diperbolehkan bernilai low pada saat yang bersamaan.

Untuk mendapat gerakan mobile robot yang sesuai dengan yang diharapkan, diperlukan kombinasi kerja dari kedua motor tersebut. Agar mobile robot dapat bergerak maju secara lurus maka kedua motor di sisi kiri dan kanan harus sama-sama berputar maju (on), sedangkan untuk bergerak mundur secara lurus maka kedua motor di sisi kanan dan kiri harus berputar dengan arah sebaliknya, reverse. Sementara itu agar mobile robot tersebut berbelok salah satu motor harus berputar (arah maju) sedangkan motor satunya lagi dalam keadaan off. Pada saat motor kanan on dan motor kiri off, maka mobile robot akan berputar ke arah kiri, sebaliknya pada saat motor kanan off dan motor kiri on, maka mobile robot akan berputar ke arah kanan.

Seperti telah disebutkan sebelumnya, bahwa pengendalian pergerakan mobile robot dilakukan dengan cara switch on-off, hal tersebut mengakibatkan kecepatan pergerakan dari mobile robot tersebut relatif konstan. Kecepatan gerakan mobile robot dipengaruhi oleh 
kemampuan motor yang digunakan, tanpa dapat dilakukan pengendalian kecepatan dengan memberikan percepatan atau perlambatan.

\section{KESIMPULAN}

Telah berhasil dilakukan penelitian Purwarupa Pengendalian Jarak Jauh Pada Mobile Robot Berbasis Web Melalui Jaringan Wireless TCP/IP. Berdasarkan pada hasil pengujian dan analisis percobaan mobile robot yang telah dilakukan, jarak optimal pengendalian dari mobile robot tidak lebih dari 7,2 meter, dengan tanpa adanya penghalang (line of sight) antara pengendali dengan mobile robot. Kemampuan kualitas streaming video untuk surveillance, mobile robot optimal ialah pada tingkat resolusi $1024 \times 720$ dengan framerate $30 \mathrm{fps}$, yang menggunakan resource CPU 1,6\%, dengan arah sudut pandang web camera yang bersifat tetap. Kemampuan arah pergerakan mobile robot ini telah sesuai dengan perintah yang diberikan oleh user melalui web browser, meski belum dapat melakukan perubahan kecepatan pergerakan baik dengan percepatan maupun perlambatan.

Beberapa hal dapat dilakukan untuk penelitian dan pengembangan selanjutnya. Diantaranya adalah Pengembangan mobile robot yang memungkinkan untuk dikendalikan meski terdapat berbagai penghalang seperti diniding atau dari ruangan yang berbeda, seperti dengan memperkuat sinyal WiFi. Peningkatan jarak optimal kendali mobile robot, yang dapat dilakukan dengan cara memasang repeater atau memperluas jaringan WLAN mobile robot atau memberikan IP Public pada mobile sehingga terhubung dengan jaringan internet dan dapat diakses dari mana saja tanpa ada batasan. Peningkatan kemampuan yang memungkinkan pengendalian arah sudut pandang dari web camera pada mobile robot, sehingga cakupan area yang dapat dipantau menjadi lebih luas. Peningkatan kemampuan mobile robot untuk dapat bergerak secara lebih dinamis dengan melakukan percepatan dan perlambatan.

\section{DAFTAR PUSTAKA}

[1] Halim, S., 2007, Merancang Mobile Robot Pembawa Objek Menggunakan OOPic-R, Elex Media Komputindo, Jakarta.

[2] Wong, C. dan Rydgren A., 2003, Controlling Bluetooth Mini Race Car from the P900, http://developer.sonyericsson.com/site/global/techsupport/tipstrickscode/java/p_tips_java_ 1202.jsp

[3] Rahmani, B., Putra, A.E., Harjoko, A., dan Priyambodo, T.K., 2015, Reveiew of Vision Based Robot Navigation Method. IAES International Journal of Robotics and Automation (IJRA), 4(4), 31-38. http://doi.org/10.11591/ijra.v4i4.8514

[4] Anadhar, 2007, Al Qur'an dan Teknologi Sensor Robot, http://www.anadhar.multiply.com/journal/item/11, diakses pada tanggal 28 Agustus 2012.

[5] Rahmani, B., Harjoko, A., Priyambodo, T.K., dan Aprilianto, H., 2016, Research of smart real-time robot navigation system. In AIP Conference Proceedings. http://doi.org/10.1063/1.4940853

[6] Raspberry Pi, 2013, Raspberry Pi, http://www.raspberrypi.org, diakses pada tanggal 15 Februari 2013. 